\title{
Macroeconomic Dynamics in Four Selected New Member States of the EU
}

Pasquale Foresti, Ugo Marani, Giuseppe Piroli

ISSN: 2031-4892

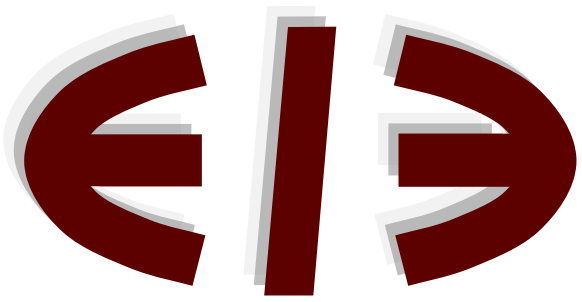

EERI

Economics and Econometrics Research Institute Avenue de Beaulieu 1160 Brussels Belgium

Tel: +3222988491

Fax: +3222988490

www.eeri.eu 


\title{
Macroeconomic Dynamics in Four Selected New Member States of the EU
}

\author{
Pasquale Foresti \\ Magna Graecia University of Catanzaro \\ foresti@unicz.it \\ Ugo Marani \\ Federico II University of Naples \\ marani@unina.it \\ Giuseppe Piroli \\ Federico II University of Naples and EERI \\ giuseppe.piroli@unina.it
}

December 2013

\begin{abstract}
In this paper, we employ a block structured near-vector autoregression in order to compare the reactions to euro-area shocks in four New Member States (Bulgaria, Hungary, Czech Republic and Romania) and in the Old Member State of the EU. Thanks to the methodology adopted we also study the effects of national economic policies and their reactions to national shocks in each New Member State. Our analysis highlights that possible asymmetric effects of the ECB's monetary policy cannot be excluded and that the potential accession of the New Member States may increase the level of fiscal indiscipline in the eurozone.
\end{abstract}

Keywords: Monetary Union, Monetary and Fiscal Policies Interaction, Economic Shocks.

JEL classification: E52, E61, F33, F36. 


\section{Introduction}

In May 2004 the European Union (EU) has begun a process of enlargement thanks to the candidatures of some New Member States (NMS). On 1 May 2004 ten NMS (Czech Republic, Estonia, Cyprus, Latvia, Lithuania, Hungary, Malta, Poland, Slovenia and Slovakia) joined the EU and in January 2007 they were followed by other two (Bulgaria and Romania). The formal EU accession did not mean the end of the integration effort of the NMS, as they aimed at entering the eurozone. This is confirmed by the fact that none of the NMS requested a dispensation and no opt-out options were granted. In order to adopt the euro, these countries are expected to achieve the economic criteria requested for entering the third EMU stage. Some NMS (namely Slovenia in 2007, Cyprus and Malta in 2008, Slovakia in 2009 and Estonia in 2011) have already reached the third stage and adopted the euro, while Latvia and Lithuania declared the intention to adopt the common currency in 2014 and 2015 respectively. The remaining five NMS (Poland, Czech Republic, Hungary, Romania and Bulgaria) are committed to enter the third stage upon the time of complying with all convergence criteria and are all expected to qualify for the adoption of the euro between 2016 and 2020.

According to the optimum currency areas theory (see Mundell, 1961; McKinnon, 1963; Kenen, 1969; and De Grauwe, 2012), the enlargement of the eurozone features several problematic aspects that require a solution before admitting each NMS in the eurozone (see Foresti, 2013; and De Grauwe and Senegás, 2004). One of these concerns the degree of symmetry in the reactions to common shocks between the NMS and the Old Member States (OMS), as the presence of asymmetric reactions casts doubts on the effective benefits of the enlargement. It is extremely important that all the countries in the eurozone show symmetric reactions to common monetary policy of the European Central Bank (ECB). In the presence of asymmetric reactions to monetary policy, the decision process of the ECB is troubled and the overall effects of its decisions are undermined. On the other side, one of the two blocks (NMS or, less likely, OMS) may encounter the situation in which the monetary maneuver is too strong, too weak or even opposite with respect to its needs. Therefore, the presence of symmetric monetary policy transmission mechanisms among countries is fundamental for the functioning of the enlarged monetary union. Moreover, the common monetary policy is supposed to be conducted on the basis of aggregated macroeconomic data. Therefore it is also important to measure the degree of synchronization of the reactions to euro-area shocks in some macroeconomic indicators like GDP and prices. Another controversial aspect of the eurozone enlargement concerns the fact that, once entered the euro-area, the NMS will face the additional challenge of combining economic and monetary integration in the EU with their domestic goals. They will loose the instrument of national monetary policies and their fiscal policies are supposed to be coordinated with the OMS and satisfy the restrictive criteria of the eurozone on public spending and debt. Based on these issues many studies have investigated the level of synchronization between the NMS and the OMS on several aspects, but no general agreement has been achieved in the literature. Some studies have highlighted a scarce level of synchronization (see Frenkel and Nickel, 2005; Horvath and Rátfai, 
2004; Artis et al, 2004; Darvas and Szapary, 2008; and Eichmer and Breitung, 2005), while others have not evidenced any significant cost for the enlargement of the euro area (see Anzuini and Levy, 2007; Fidrmuc and Korhonen, 2006; and Duemmler et al, 2012). Ben Arfa (2009), among several countries, finds that Czech Republic and Hungary seem to be ready to adopt the euro, while Bulgaria and Romania show low level of correlation with the euro-area.

Therefore, it is very important to asses the effects of monetary and fiscal policy in the NMS and how the two policies interact in order to form the policy-mix. The understanding of such aspect has two important functions. First, it allows assessing what the NMS are loosing, in terms of economic policy, once entered the eurozone. Second, focusing on the conduct of national fiscal policies, it is possible to evaluate the potential imbalances for the eurozone due to the entrance of the NMS.

In this paper, we provide new empirical evidence on the above-mentioned problems by employing a block structured near-vector autoregression, in which we distinct between a block with euro area-wide variables and several blocks with NMS individual variables. Thanks to this technique we are able to compare the reactions to euro-area shocks in the single NMS and in the OMS, but we are also able to study the effects of national economic policies and their reactions to national shocks in each NMS.

We focus of four NMS (namely Romania, Bulgaria, Czech Republic and Hungary), and our sample is based on quarterly data spanning the period 1998:Q1-2012:Q4.

We find that the reactions to shocks in Bulgaria, Czech Republic and Hungary show good levels of synchronization with the reaction in the euro-area countries, while the evidence for Romania is more mixed with some evidences of potentially asymmetric reactions.

The rest of the paper is structured as follows. We discuss our methodology and dataset in section 2. Then, the results of our study are presented in sections 3 and 4 . We analyze the reactions to euro-area common shocks in the NMS in section 3, and we compare them to the impulse-response in the euro-area. We discuss the effects and the conduct of national economic policies in the NMS in section 4, and we compare them among the single NMS. In section 5 we conclude the paper by providing also some policy implications.

\section{Data and Methodology}

Following the majority of the empirical literature that studies the effects of common shocks in different countries, we adopt an extended version of a structural VAR. In particular, we estimate a block structured near-VAR that modifies the model adopted by Peersman (2004). Our model has the following representation:

$$
\left[\begin{array}{c}
X_{t} \\
Z_{t}^{1} \\
Z_{t}^{2} \\
\vdots \\
Z_{t}^{n}
\end{array}\right]=\left[\begin{array}{ccccc}
A(L) & 0 & 0 & \ldots & 0 \\
B(L) & C(L) & 0 & \ldots & 0 \\
D(L) & 0 & E(L) & \ldots & 0 \\
\vdots & \vdots & \vdots & \ddots & 0 \\
F(L) & 0 & 0 & \ldots & G(L)
\end{array}\right]\left[\begin{array}{c}
X_{t-1} \\
Z_{t-1}^{1} \\
Z_{t-1}^{2} \\
\vdots \\
Z_{t-1}^{n}
\end{array}\right]+S\left[\begin{array}{c}
\varepsilon_{t}^{x} \\
\varepsilon_{t}^{y^{1}} \\
\varepsilon_{t}^{y^{2}} \\
\vdots \\
\varepsilon_{t}^{y^{n}}
\end{array}\right]
$$


The variables included in the model are divided into $n+1$ blocks. The first block, $X_{t}$, contains the following aggregated euro-area variables:" Prices $\left(p_{t}^{E A}\right)$, real GDP $\left(y_{t}^{E A}\right)$ and a short-term interest rate $\left(r_{t}^{E A}\right)^{\prime}$. Then:

$$
X_{t}=\left[\begin{array}{lll}
y_{t}^{E A} & p_{t}^{E A} & r_{t}^{E A}
\end{array}\right]
$$

The blocks $Z_{t}^{i}$, with $i \in[1, . . n]$, contain the variables of the single NMS. For each individual country " $i "$, the variables included are: real GDP $\left(y_{t}^{i}\right)$, the price level $\left(p_{t}^{i}\right)$, the primary balance surplus/deficit $\left(d_{t}^{i}\right)$ and short-term interest rate $\left(r_{t}^{i}\right)$. Therefore:

$$
Z_{t}^{i}=\left[\begin{array}{llll}
y_{t}^{i} & d_{t}^{i} & p_{t}^{i} & r_{t}^{i}
\end{array}\right]
$$

The main advantage of this methodology is that we can evaluate the effects of the same euro-area shocks in each NMS and in the euro-area as a whole. At the same time we can also analyze the effects of national macroeconomic policies in each NMS, and compare the reaction functions across them. This structure ensures that the euroarea estimates are not influenced by the country-specific variables and the number of individual country blocks. It is also possible to take into account spillover effects between countries, but from equation (1) it is clear that we do not allow for any impact across the individual country blocks in the system in order to have enough degrees of freedom to estimate the whole system. It is worth noting that the same results for the euro-area as a whole can be found if the sole aggregate block is estimated separately without the individual country blocks (this specification has been adopted in Peersman and Smets, 2001). In order to conduct our impulse-response analysis, we identify the shocks relying on the standard Cholesky decomposition (see Sims, 1980), which only requires to specify the order of the variables. Indeed, we assume that the ordering of the blocks follows equation (1) and that the variables within the blocks are ordered as in equations (2) and (3). These assumptions impose a recursive scheme to the contemporaneous correlations in the system estimated. The first variable reacts only to its own innovation, the second variable responds to first variable shock and its own innovation and so on for the others variables. In this way, we have a last variable which immediately responds to all the innovations of the other variables in the system, but a shock in this variable does not produce any contemporaneous effect on the other variables. In other words, each variable responds only to previous variable shock and to its own innovations. From the economic point of view, we assume that price variables react faster than real one. In fact, according to our identification strategy, we have that, for example, the production (GDP) immediately affects price level and short-term interest rate, while the inverse effects are only lagged.

In our estimation we focus of four NMS (namely Romania, Bulgaria, Czech Republic and Hungary), and then we can set that $n=1, \ldots, 4$ in equation (1). Our sample is based on quarterly data spanning the period 1998:Q1-2012:Q4 and, following BIC and SIC criteria, we estimate the model with one lag. We do not perform an explicit analysis of the long-run behavior of the economy and, by conducting the analysis in levels, we allow for implicit cointegrating relationships in the data. 


\section{Synchronization with the EMU}

In this section we report the results from the impulse-response analysis with respect to euro-area shocks. These impulse-response functions are reported In figure 1.

As a first step we study the response to a monetary policy maneuver by the ECB modeled as an unexpected increase of one standard deviation in the euro-area short-term interest rate.

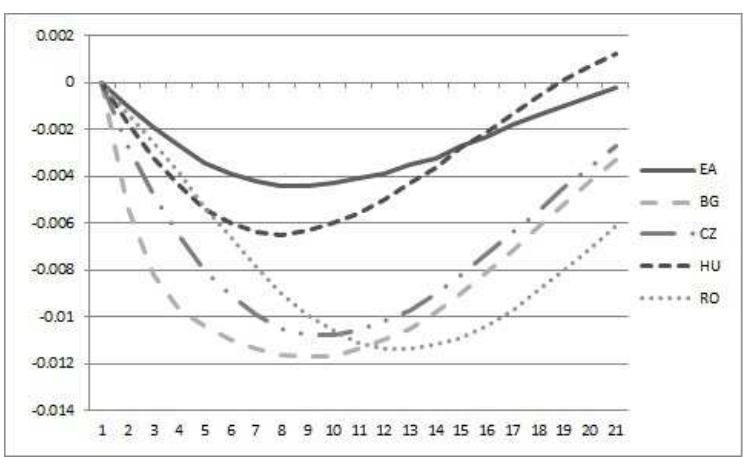

(a) Impulse: $r^{E A}$; Response: $y$

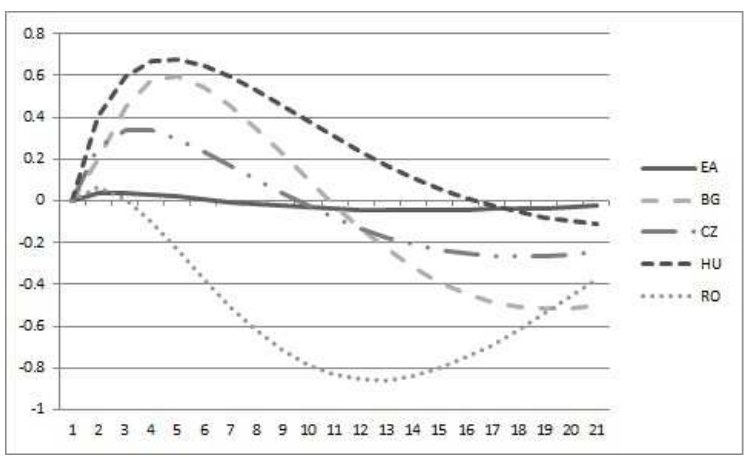

(c) Impulse: $r^{E A}$ Response: $p$

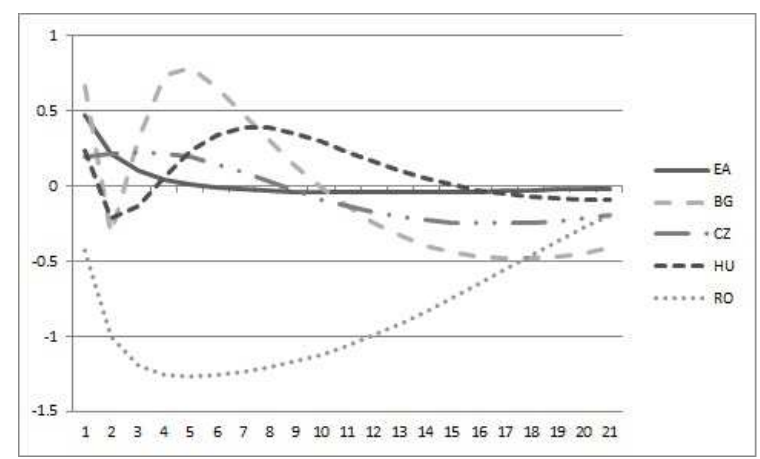

(e) Impulse: $p^{E A}$ Response: $p$

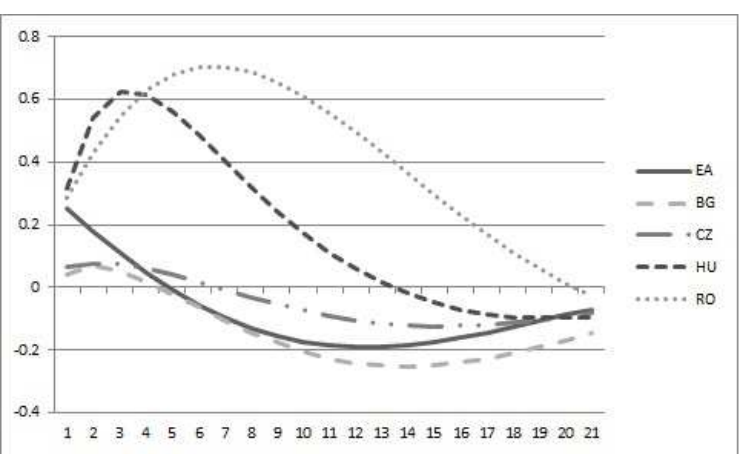

(b) Impulse: $r^{E A}$ - Response: $r$

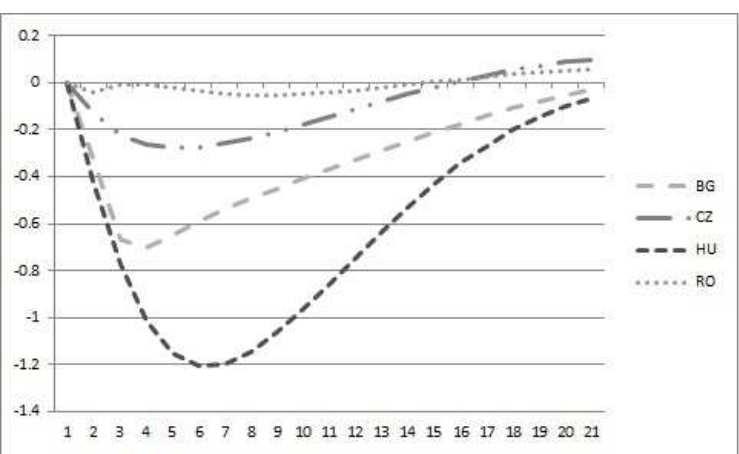

(d) Impulse: $r^{E A}$ Response: $d$

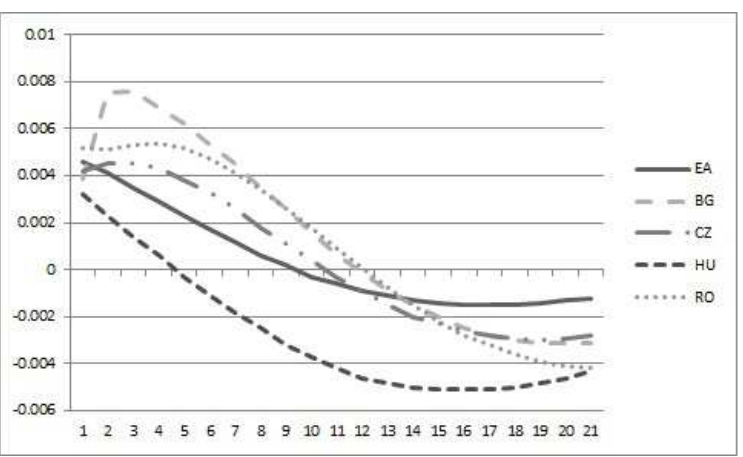

(f) Impulse: $y^{E A}$ Response: $y$

Figure 1: Impulse-Response Analysis to Macroeconomic Shocks in the Euro-Area

Panel $(a)$ shows the response of GDP in the euro-area and in each NMS to a monetary shock in the eurozone. The impulse-responses highlight results in line with economic theory, as an increase in the interest rate reduces the GDP in all NMS and in 
the euro-area considered as a whole. Moreover, all the NMS and the euro-area block show a similar (symmetric) response to the monetary policy shock. Nevertheless, Bulgaria, Czech Republic and (especially) Romania have a more sluggish adjustment. Table 1 also reports the correlation between the impulse-response functions in the euro area and in each NMS. As a confirmation of the visual investigation, the GDP reaction in Bulgaria, Czech Republic and Hungary show strong synchronization with the GDP response in the euro-area, while Romanian GDP reaction highlights a significant lower level of co-movement.

Panel (b) reports the impulse responses of the interest rate variable to an euro-area monetary policy shock. It is clear that the estimated impulse-response in Bulgaria and Czech Republic are very similar to the one in the euro-area. On the contrary, Hungary and Romania show different paths with a more persistent initial increase in their interest rates. More specifically, figure 2 highlights asymmetric responses for the first 4 and 8 quarters in Hungary and Romania respectively. Such features result in high levels of impulse-response functions correlation with the euro-area for Bulgaria (0.93) and Czech Republic (0.86), a lower level for Hungary (0.64) and even an almost null correlation for Romania (0.04).

Panel (c) shows the impulse response functions of the price indicator to a monetary policy shock. It is worth noticing that the typical price puzzle arises for three countries (Bulgaria, Czech Republic and Hungary). Therefore the results from this analysis should be treated with caution. Besides this problem the analysis show a relevant synchronization with the OMS in the dynamic of the price response.

In panel $(d)$ the responses of the NMS primary balance to a monetary shock in the eurozone are reported. The impulse-response analysis highlights that national governments in the NMS react to changes in the interest rate in the euro-area. The sign of their reactions are in line with economic theory, as following an increase in the interest rate national governments react with expansionary fiscal policies in order to stabilize the contractionary effects of the monetary policy (see Beetsma and Debrun, 2004; and Foresti and Marani, 2013). Moreover, the estimated impulse-responses show similar paths among the NMS, although the reaction in the primary balance of Romania is less pronounced with respect to the other three NMS.

In order to further evaluate the synchronization with the euro-area, we also investigate the reaction of the price indicator and the GDP in the NMS, following a shock to the same variable in the euro-area. Figure 1 panel $(e)$ shows a poor synchronization of the price indicator reaction to a shock to the same variable in the eurozone. This result is not surprising as, although the NMS have achieved considerable macroeconomic stabilization over the past decade, they went through the transition from central planning to market economies, which began with high inflation and financial instability. Moreover, the fact that they do not have adopted the euro yet, allows for asymmetric behaviors in their national prices indicators in response to a shock to the euro-area prices indicator. Panel $(f)$ shows the response of GDP to a shock to the euro-area GDP. It shows that all the NMS reactions to such shock are strongly synchronized with the euro-area. 
Table 1: Impulse-response correlation

\begin{tabular}{lcccc}
\hline \hline Impulse-Response & \multicolumn{4}{c}{ Countries } \\
& Bul & $\mathrm{Cz}$ & Hun & Rom \\
\hline \hline & & & & \\
$r^{E A}-y^{i}$ & 0.969 & 0.968 & 0.963 & 0.566 \\
$r^{E A}-r^{i}$ & 0.933 & 0.861 & 0.642 & 0.041 \\
$r^{E A}-p^{i}$ & 0,783 & 0,912 & 0,693 & 0,901 \\
$p^{E A}-p^{i}$ & 0,371 & 0,581 & $-0,087$ & 0,138 \\
$y^{E A}-y^{i}$ & 0.911 & 0.952 & 0.997 & 0.894 \\
\hline \hline
\end{tabular}

\section{National Economic Policies Effects in the NMS}

We perform a standard VAR for each country in order to check for country specific effects from both national fiscal and monetary policies. In this case we do not use a near-VAR approach, because we focus our attention on the effects that national policies in NMS produce within each single country. In this way, using the same variables as before, we obtain four different estimated models and related impulseresponse functions. In this section, we are mainly interested in checking whether the four countries analyzed exhibit consistent national economic policies or if some of them highlight peculiar dynamics in the pattern of economic fundamentals. In particular, we investigate if, at national level, monetary and fiscal policies pursue coherent targets or seek different aims. At the same time, we wonder if the different countries exhibit similar behaviors or highlight differences in terms of both economic policies and reactions to the shocks. Figures 2 to 5 present some impulse response functions for our four countries.

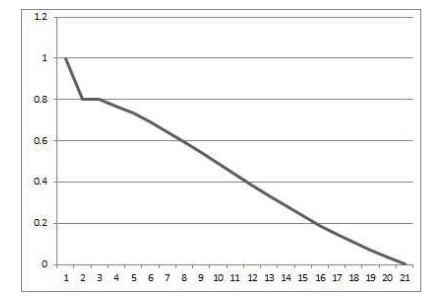

(a) Imp: $y$ Resp: $d$

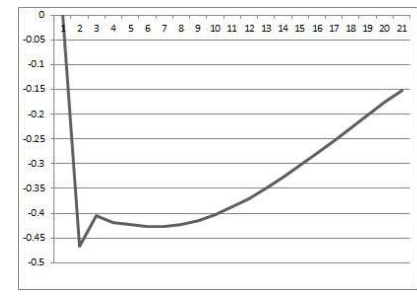

(d) Imp: $r$ Resp: $d$

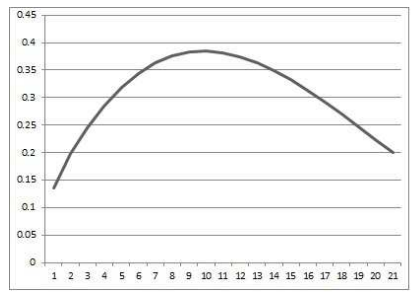

(b) Imp: $y$ Resp: $r$

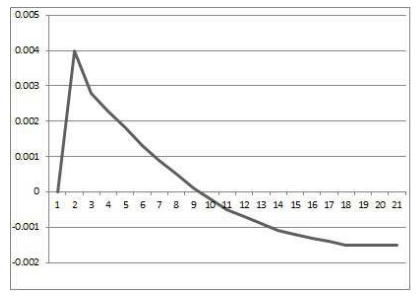

(e) Imp: $d$ Resp: $y$

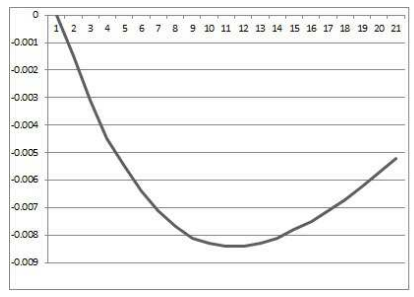

(c) Imp: $r$ Resp: $y$

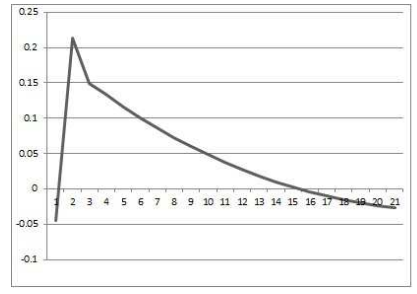

(f) Imp: $d$ Resp: $r$

Figure 2: Bulgaria. Impulse-Response Analysis to National Shocks 


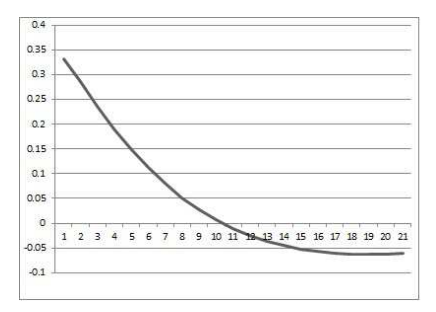

(a) Imp: $y$ Resp: $d$

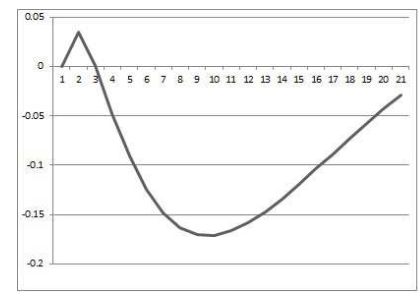

(d) Imp: $r$ Resp: $d$

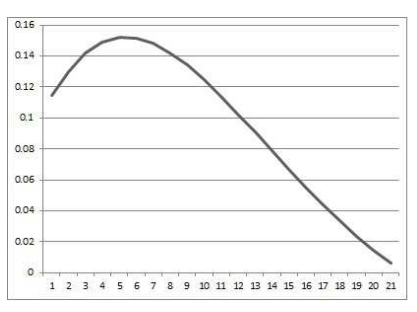

(b) Imp: $y$ Resp: $r$

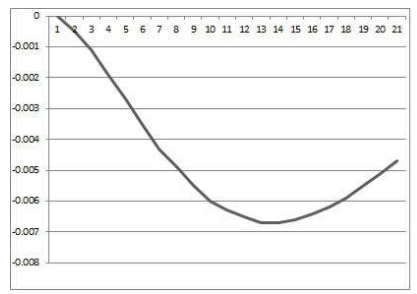

(e) Imp: $d$ Resp: $y$

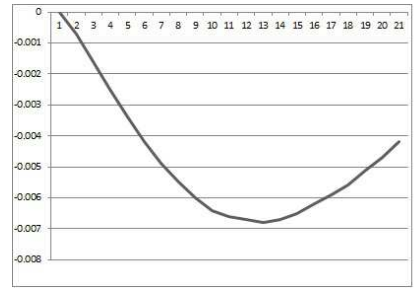

(c) Imp: $r$ Resp: $y$

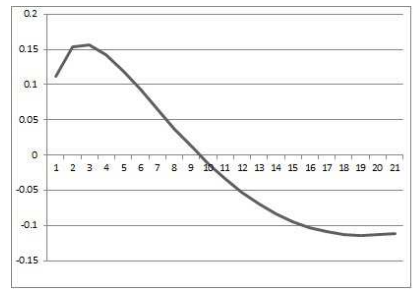

(f) Imp: $d$ Resp: $r$

Figure 3: Czech Republic. Impulse-Response Analysis to National Shocks

Bulgaria and Czech Republic show overall very similar behaviors. The impulse response functions show that in these two countries economic policies are used as tools for anti-cyclical purposes. In fact, an innovation in GDP implies a positive variation in both primary balance and interest rate for both Bulgaria and Czech Republic (see figures 2 and 3 panels a and b). At the same time, the effects of national monetary policy shocks on GDP is consistent with expectations, as restrictive maneuvers (an increase in the interest rate) have a negative impact on GPD (see figures 2 and 3 panel c). Fiscal policy shocks have mainly "Keynesian" effects, as a positive shock in primary balance determines a reduction in GDP in Czech Republic (see figure 3 panel $e)$. The same happens in Bulgaria, with the only difference that the overall negative effect follows an initial increase in GDP (see figure 2 panel $e$ ). In both countries following a monetary policy shock the reaction of fiscal policy aims at stabilizing its effects, as following an increase of one standard deviation in the interest rate the primary balance has a negative reaction (see figures 2 and 3 panel $\mathrm{d}$ ). In Bulgaria the reaction of the interest rate is positive after the increase in the primary budget (see figure 2 panel $\mathrm{f}$ ), and this is interpreted as the central bank supporting the fiscal policy maneuvers. In Czech Republic one innovation in the primary deficit increases the interest rate immediately and the reaction remains positive for the first ten quarters.

Romania, instead, appears to pursue a coherent anti-cyclical economic policy conduct only partially. In fact, interest rate significantly increases following an innovation in GDP (see figure 4 panel b), while primary balance reacts negatively after the same shock (see figure 4 panel a). Therefore from our impulse response analysis it seems that in this country monetary policy reacts anti-cyclically to a GDP shock, while fiscal policy reacts pro-cyclically. Concerning the effects of monetary and fiscal policies on the level of economic activity, an increase in the interest rate determines a decrease in GDP and we can also observe an overall negative impact of primary balance on 
GDP following a small positive effect which stands for six quarters (see figure 4 panel c and e). Moreover, monetary and fiscal policies appear to reinforce each other in the long-run. The interest rate is positively and persistently affected by one innovation in the primary balance (see figure 4 panel $\mathrm{f}$ ). At the same time, one innovation in the interest rate affects positively the primary balance after 10 quarters (see figure 4 panel d).

Conversely, Hungary appears to have a rather different economic policy behavior. A large expansion of the primary budget follows an innovation in GPD, while interest rate immediately decreases in response to an increase in GDP (see figure 5 panel $\mathrm{a}$ and $\mathrm{b}$ ). Therefore, fiscal policy appears to react pro-cyclically to shocks to the GDP, while monetary policy seems to react counter-cyclically. The effects of fiscal and monetary policies on GDP reflects standard economic theories implications, as both an improvement in the primary budget and an increase in the interest rate negatively affect the GDP (see figure 5 panel $\mathrm{c}$ and e). Concerning the interaction between monetary and fiscal policy, a positive shock to the interest rate determines the contraction of the public primary budget, while one innovation in the latter is followed by a positive reaction of the interest rate (see figure 5 panel $\mathrm{d}$ and $\mathrm{f}$ ).

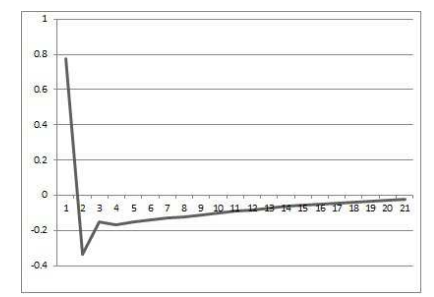

(a) Imp: $y$ Resp: $d$

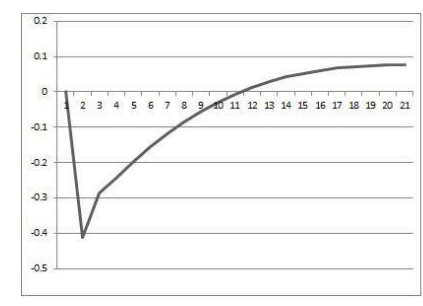

(d) Imp: $r$ Resp: $d$

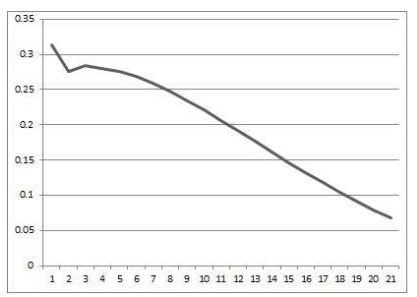

(b) Imp: $y$ Resp: $r$

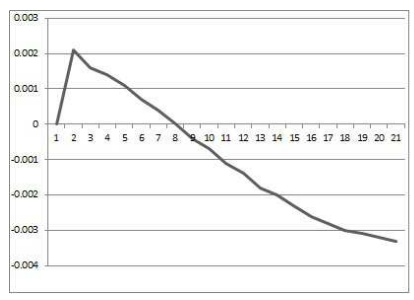

(e) Imp: $d$ Resp: $y$

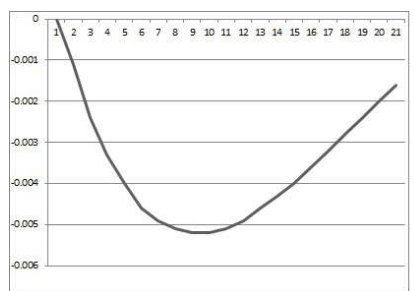

(c) Imp: $r$ Resp: $y$

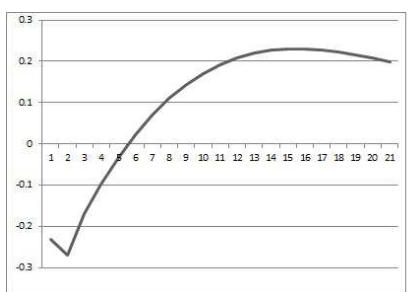

(f) Imp: $d$ Resp: $r$

Figure 4: Romania. Impulse-Response Analysis to National Shocks

\section{Conclusion}

In this paper we have focused on some relevant aspects of the integration process of some NMS (namely Romania, Bulgaria, Czech Republic and Hungary) and the OMS of the euro-area. To this aim we have estimated a block-structured near VAR.

First, we have analyzed the reaction to euro-area shocks in the OMS considered as a whole and in each NMS. This analysis has provided some insights to understand the likelihood of asymmetric reactions to euro-area shocks in the enlarged EU. The 


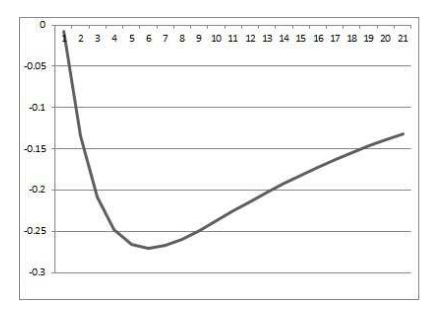

(a) Imp: $y$ Resp: $d$

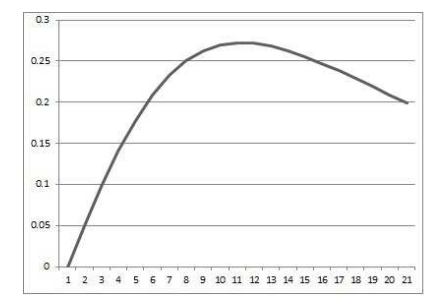

(d) Imp: $r$ Resp: $d$

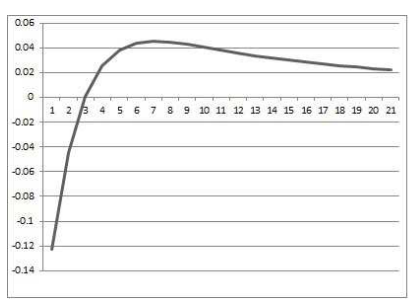

(b) Imp: $y$ Resp: $r$

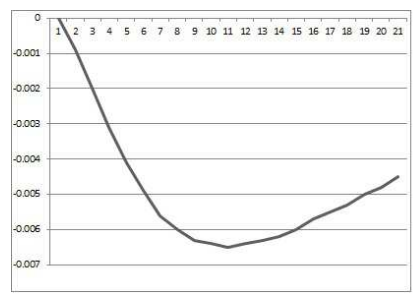

(e) Imp: $d$ Resp: $y$

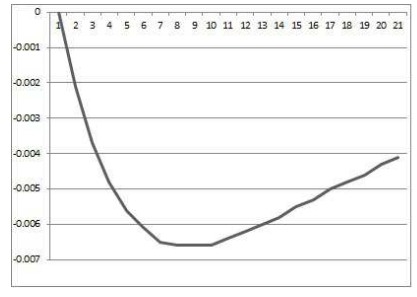

(c) Imp: $r$ Resp: $y$

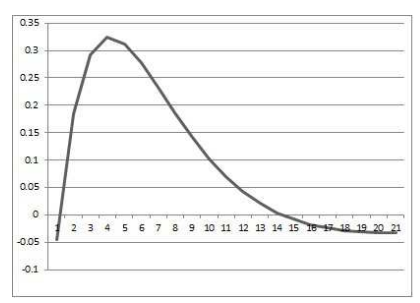

(f) Imp: $d$ Resp: $r$

Figure 5: Hungary. Impulse-Response Analysis to National Shocks

impulse-response analysis has highlighted that the reaction to euro-area shocks in Czech Republic and Bulgaria are quite similar to the reactions in the OMS. On the contrary, the estimated reactions in Hungary and Romania have showed less synchronized dynamics, to the extent that possible asymmetric effects of monetary policies cannot be excluded in these two countries.

Secondly, we have studied the macroeconomic effects of national shocks in each NMS and how national monetary and fiscal policies seem to interact at national level in each NMS. The analysis concerning the reaction of the fiscal policy variable to shocks allows understanding how the accession of the NMS may affect the general problem of the control of national fiscal policies conduct in the EU. Moreover, the analysis of the national monetary policy effects and reactions permits to understand what the single NMS would loose in terms of economic policy effectiveness once they enter the euro-area. National fiscal policies seem to react to the ECB's monetary policies aiming at stabilizing these effects. Therefore, a restrictive monetary maneuver is supposed to be followed by expansionary fiscal policies in all the four NMS. Concerning the reaction of fiscal policy to national shocks more heterogeneity is evidenced. Romania and Bulgaria seem to conduct their fiscal polices with strong anti-cyclical aims, Romania seems to apply this approach only partially, while Hungary seems to react in a completely opposite way. Therefore, it seems that the potential accession of the NMS (especially Hungary and Romania) may increase the level of fiscal indiscipline in the eurozone. On the side of monetary policies it seems that all the four countries have a national monetary policy that consistently affect macroeconomic variables, therefore once entered the euro-area they will all loose a strong policy instrument to stabilize the economy. 


\section{References}

[1] Anzuini, A. and Levy, A, (2007) monetary Policy Shocks in the New EU Members: A VAR Approach, Applied Economics, Taylor and Francis Journals, Vol. 39(9), pp. 1147-1161.

[2] Artis, M., Marcellino, M. and Proietti, T. (2004) Characterising the Business Cycle for Accession Countries, CEPR Discussion Papers 4457, C.E.P.R. Discussion Papers.

[3] Beetsma, R.M.W.J. and Debrun. X. (2004) The Interaction Between Monetary and Fiscal Policies in a Monetary Union: a Review of Recent Literature. In Beetsma R., Favero C., Missale A., Muscatelli A., Natale P., Tirelli P. (eds) Monetary Policy, Fiscal Policies and Labour Markets: Macroeconomic Policymaking in the EMU. Cambridge University Press.

[4] Ben Arfa, N. (2009) Analysis of Shocks Affecting Europe: EMU and some Central and Eastern Acceding Countries, Panoeconomicus, Vol 1, pp. 21-38.

[5] Darvas, Z. and Szapary, G. (2008) Business Cycle Synchronization in the Enlarged EU, Open Economies Review, Vol. 19, pp. 1-19.

[6] De Grauwe, P. (2012) The Economics of Monetary Union. Oxford University Press, Oxford.

[7] De Grauwe, P., Sénégas, M.A. (2004) Asymmetries in Monetary Policy Transmission: Some Implications for EMU and its Enlargement. Journal of Common Market Studies, Wiley Blackwell, Vol. 42, No. 4, pp. 757-773, November.

[8] Duemmler, T., Eissrich, D. and Kienle, S. (2012) Alignment to the Eurosystem: Some Findings from a VAR Approach for Selected CEE Countries, International Journal of Economic Policy in Emerging Economies, Vol. 5, No. 1, pp. 37-46.

[9] Eichmer, S. and Breitung, J. (2005) How Synchronized are Central and East European Economies with the Euro-Area? Evidence from a Structural Factor Model, TWI Research Paper Series 14, Thugauer Wirtschaftsinstitut, Universitat Kostanz.

[10] Fidrmuc, J. and Korhonen, I. (2006) Meta-Analysis of the Business Cycle Correlation between the Euro Area and the CEECs. Journal of Comparative Economics, Vol. 34, pp. 518-537.

[11] Foresti, P. (2013) How do Debt Constraints Affect Fiscal and Monetary Policies Interaction in a Strategic Monetary Union? Journal of Game Theory. Vol. 2, No. 2, pp. 13-17.

[12] Foresti, P. and Marani, U. (2013) Fiscal Indiscipline and Monetary Policy in the EMU: Is There any Need for a Fiscal Policy Concerned ECB? International Journal of Monetary Economics and Finance, Vol 6, No. 1, pp. 81-95. 
[13] Frenkel, M. and Nickel, C. (2005) How Symmetric are Shocks and the Shock Adjustment Dynamics between the Euro Area and the Central and Eastern European Countries? Journal of Common Market Studies, Vol 43, No. 1, pp. 53-74.

[14] Horvath, J. and Rátfai, A. (2004) Supply and Demand Shocks in Accession Countries to the Economic and Monetary Union. Journal of Comparative Economics, Vol. 32, pp. 202-211.

[15] McKinnon, R. I. (1963) Optimum Currency Areas. American Economic Review, Vol 53, No. 4, pp. 717-725, September.

[16] Mundell, R. A. (1961) A Theory of Optimum Currency Areas. American Economic Review, Vol. 51, No. 4, pp. 657-665.

[17] Peersman, G. (2004) The Transmission of Monetary Policy in the Euro Area: Are the Effects Different Across Countries?. Oxford Bulletin of Economics and Statistics, Department of Economics, University of Oxford, Vol. 66, No. 3, pp. 285-308.

[18] Peersman, G. and Smets, F. (2001) The Monetary Transmission Mechanism in the Euro Area: More Evidence from VAR Analysis. European Central Bank Working Paper Series, No. 91.

[19] Sims, C. A. (1980) Macroeconomics and Reality. Econometrica, Vol.48, No 1, pp. 1-48.

[20] Kenen, P. (1969) The Theory of Optimum Currency Areas: An Eclectic View, in R. Mundell and A. Swoboda (eds), Monetary Problems of the International Economy, Chicago: University of Chicago Press (1969), pp.41-60. 